\title{
COMPARATIVE AUDIT OF UPPER GASTROINTESTINAL HAEMORRHAGE
}

\section{HJ Tan, SpR in Gastroenterology; S Dayala, Medical Student; BA Teague, Clinical Audit Manager; JJ Keating, Consultant Gastroenterologist, Furness General Hospital}

\section{BACKGROUND}

Upper gastrointestinal haemorrhage is a common and potentially serious condition. The overall incidence is $103 / 100,000$ per year ${ }^{(1)}$. This increases to $485 / 100,000$ per year in those over 75 years old. The overall mortality is $14 \%$ and re-bleeding increases the mortality to $37 \%$.

The Royal College of Physicians published a national guideline in 1992 (Figure 1) (2) $^{(2)}$ and a steering committee was set up to undertake a national audit. Age, shock, comorbidity, diagnosis at endoscopy, stigmata of recent haemorrhage and re-bleeding were found to be independent risk factors of mortality ${ }^{(3)}$.

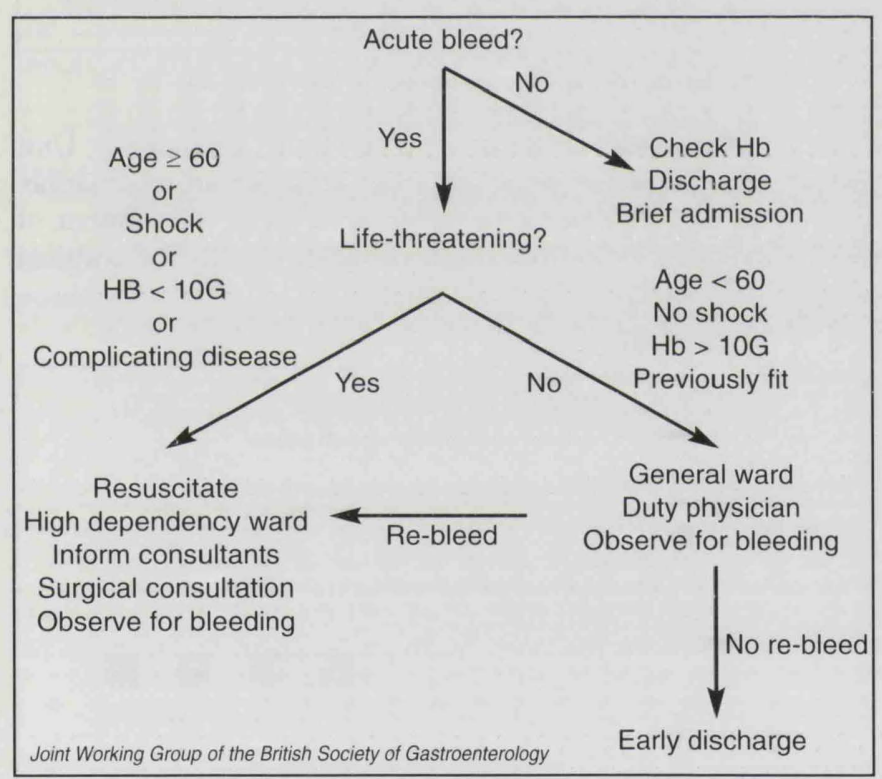

Figure 1 National guidelines

A scoring system was developed (Figure 2) to categorize patients into high and low risk groups for re-bleed and death. This enabled the identification of low risk patients suitable for early discharge, or even out-patient treatment of upper gastrointestinal haemorrhage $\mathrm{e}^{(4)}$.

Currently there are no local guidelines or a designated endoscopy rota for the management of upper gastrointestinal haemorrhage at Furness General Hospital and patients generally have to wait more than twenty-four hours for an endoscopy. We conducted this audit to identify areas for improvement in our service by comparing local practice with national guidelines.

\begin{tabular}{|l|l|l|l|l|}
\hline & \multicolumn{1}{|c|}{0} & \multicolumn{1}{|c|}{1} & \multicolumn{1}{c|}{2} & \multicolumn{1}{|c|}{3} \\
\hline Shock & \multicolumn{1}{|c|}{$<00$ yrs } & \multicolumn{1}{|c|}{$60-79$ yrs } & \multicolumn{1}{|c|}{$\geq 80$ yrs } & \\
\hline Comorbidity & $\begin{array}{l}\text { No shock } \\
\text { Systolic BP } \geq 100 \\
\text { Pulse }<100\end{array}$ & $\begin{array}{l}\text { Tachycardia } \\
\text { Systolic BP } \geq 100 \\
\text { Pulse } \geq 100\end{array}$ & $\begin{array}{l}\text { Hypotension } \\
\text { Systolic BP }<100\end{array}$ & \\
\hline comorbidity & & $\begin{array}{l}\text { Cardiac failure, } \\
\text { IHD, any major } \\
\text { comorbidity }\end{array}$ & $\begin{array}{l}\text { Renal failure } \\
\text { Liver failure } \\
\text { Disseminated } \\
\text { maliganancy }\end{array}$ \\
\hline Diagnosis & $\begin{array}{l}\text { Mallory-Weiss } \\
\text { tear. No lesion } \\
\text { No SRH }\end{array}$ & $\begin{array}{l}\text { All other } \\
\text { diagnoses }\end{array}$ & $\begin{array}{l}\text { Malignancy } \\
\text { of upper GIT }\end{array}$ & \\
\hline Major SRH & $\begin{array}{l}\text { None, or dark } \\
\text { spot only }\end{array}$ & $\begin{array}{l}\text { Blood in } \\
\text { upper GIT } \\
\text { adherent clot, } \\
\text { visible or } \\
\text { spurting blood }\end{array}$ & \\
\hline
\end{tabular}

Figure 2 Rockall Risk Scoring System. The maximum score possible is 11. A score of two or less is considered low risk for rebleeding and mortality.

\section{AIMS}

The aims of the audit were

1 to formulate local guidelines for upper gastrointestinal haemorrhage and

2 to identify whether there was any delay in discharge for low risk patients.

\section{METHODS}

\section{Data collection}

The Information Department at Furness General Hospital identified patients from the ICD10 clinical coding system who had been admitted with upper gastrointestinal haemorrhage during a twelve-month period (1 July 1998 to 30 June 1999). Seventy-one cases of upper gastrointestinal non-variceal bleed involving 65 patients were identified. The medical case notes were collected for review. A standardised proforma was used for retrospective data collection which focused on age, shock, co-morbidity, diagnosis, management, length of stay, length of wait for endoscopy and mortality. A validated risk scoring system (Rockall Score) was used to identify low risk patients (Figure 2). The information was entered into EPI Info V6, a World Health Organisation computerised database and statistical package, and validity checks were made to assess the quality of data collected.

\section{Definitions}

Acute upper gastrointestinal haemorrhage was defined as the passage of melaena, or haematemesis, or coffee-ground vomitus observed by trained medical or nursing staff. Re-bleeding was defined as bleeding which occurred after a patient had been haemodynamically stabilised. 


\section{RESULTS}

Figure 3 portrays the age and sex distribution characteristics of the audit sample. The overall mean age was 61 years (female 65 years, male 58 years).

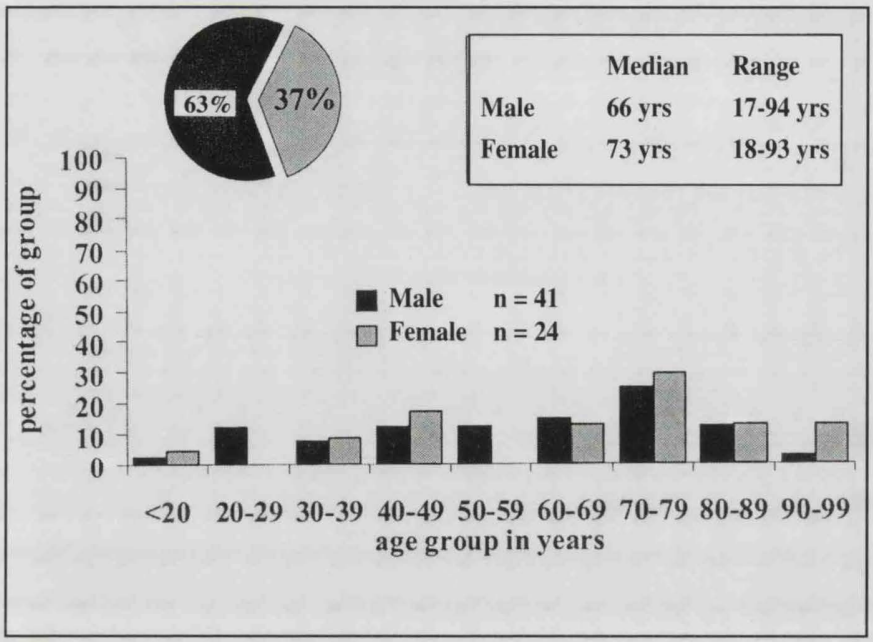

Figure 3 Gender and age distribution $(n=65)$

The overall crude mortality was $4.5 \%$ (three patients). There were 32 cases $(49 \%)$ that had one or more co-morbid condition (Figure 4).

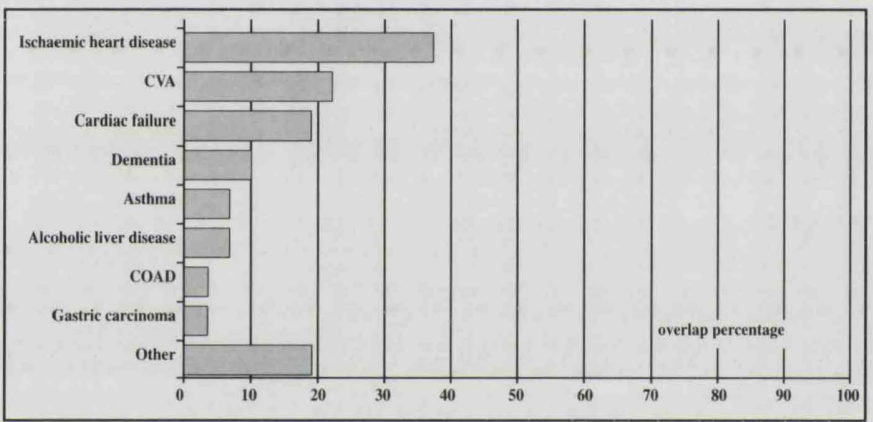

Figure 4 Co-morbidity $(n=32)$

Endoscopy was performed in 43 cases $(61 \%)$ only. Out of the 43 cases, only 28 cases $(65 \%)$ were performed as an inpatient. The median wait for an endoscopy for inpatient and outpatient endoscopy was three and 14.5 days respectively. Endoscopy was not performed in 28 cases (39\%) because the patient was stable (15), unsuitable (8) or refused to have the procedure (5). Twenty-four cases (34\%) of upper gastrointestinal bleed were non-steroidal anti-inflammatory drug-induced. The diagnosis at endoscopy is shown on Table 1.

A Rockall score was obtainable in 38 patients (54\%). The median score for our patients was three (Figure 5).

\begin{tabular}{|l|c|c|}
\hline Diagnosis & Number & $\%$ \\
\hline Normal & 16 & $37 \%$ \\
\hline Gastritis & 14 & $33 \%$ \\
\hline Oesophagitis & 8 & $19 \%$ \\
\hline Duodenal ulcer / duodenitis & 6 & $14 \%$ \\
\hline Gastric ulcer & 4 & $9 \%$ \\
\hline Mallory-Weiss tear & 1 & $2 \%$ \\
\hline Others & 4 & $9 \%$ \\
\hline
\end{tabular}

Table 1 Diagnosis at endoscopy $(n=43)$

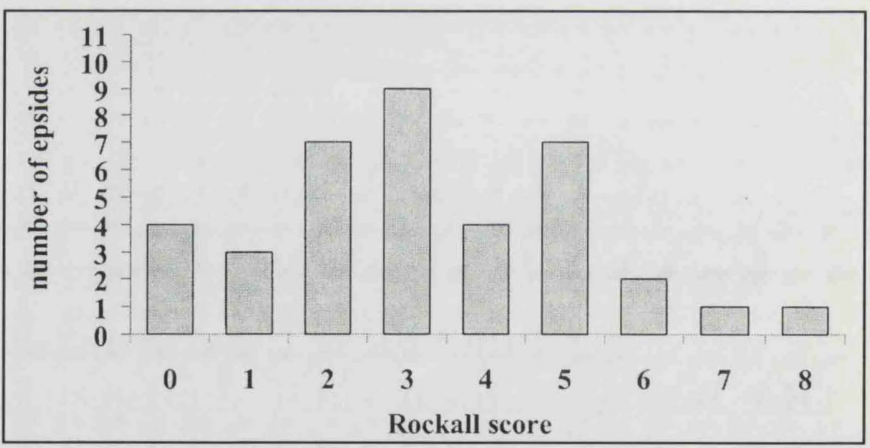

Figure 5 Rockall score $(n=38)$

The median stay for the 14 patients (37\%) scoring two or less was 3.5 days and the interval from admission to endoscopy in this group was three days (Figure 6). The length of stay increased with the rise in scores. Only twelve patients $(28 \%)$ had endoscopy within 24 hours.

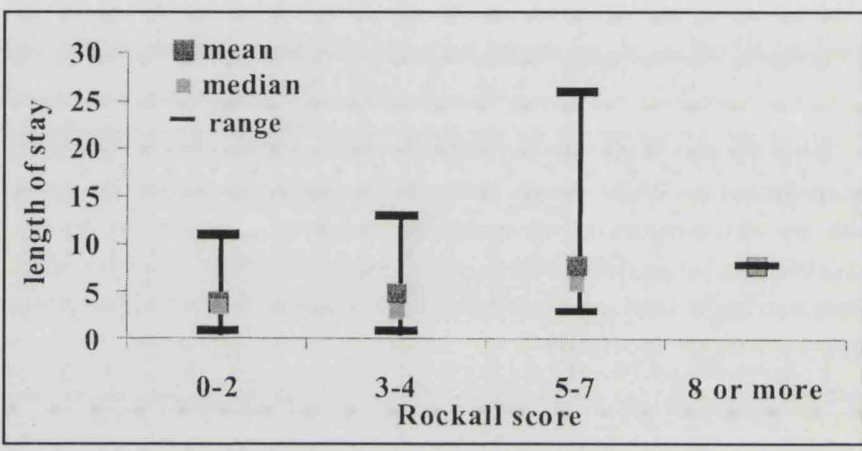

Figure 6 Rockall score vs length of stay $(n=38)$

Six patients were admitted to the High Dependency Unit (HDU) and central venous pressure was monitored in one. Only four patients were referred to a surgeon, the number of units transfused being the main deciding factor for surgical referral (Figure 7).

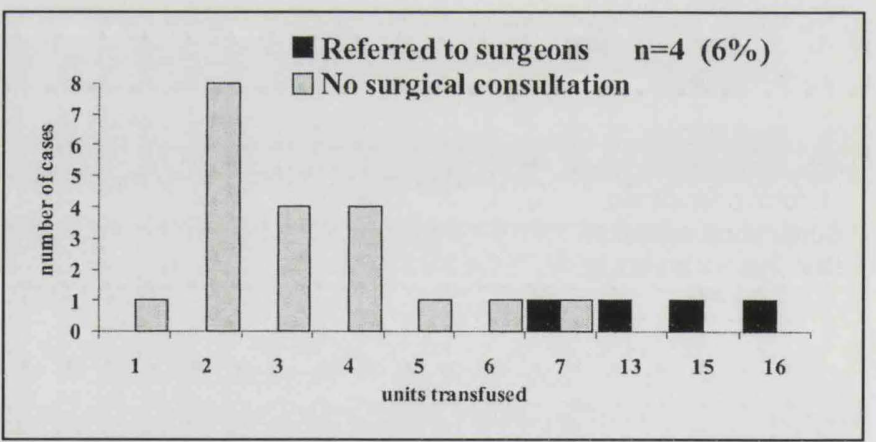

Figure 7 Blood transfusion vs referral to surgeons $(n=24)$

\section{DISCUSSION}

The audit revealed that not every patient with a presumed diagnosis of upper gastrointestinal haemorrhage had an endoscopy. Fifteen (35\%) of the 43 patients admitted had an endoscopy performed as an outpatient. There was considerable delay in some of our outpatient endoscopies. This reduced the yield for endoscopic diagnosis as shown by the normal endoscopy findings in a high proportion of the outpatients $(47 \%)$. The value of outpatient endoscopy is therefore questionable in identifying conspicuous lesions in acute upper gastrointestinal haemorrhage, as many of the lesions would have healed (eg Mallory-Weiss syndrome) with the delay in endoscopy, especially when all our patients were treated with a proton pump inhibitor. This would also explain our low rate of diagnosis of Mallory-Weiss syndrome (2\%), which would normally account for $10-15 \%$ of upper 
gastrointestinal bleeds. The main reason for outpatient endoscopy was the limited availability of places on the endoscopy lists. Some patients had to be discharged home whilst awaiting endoscopy.

Only a small number ( $28 \%$ ) of our patients had endoscopy within 24 hours. The median wait in our unit is three days, which is far from ideal. The endoscopies were mainly performed on a normal routine list. The low risk group (score 0 -2) who were stable with a very low risk of re-bleed and negligible risk of death had a median stay of 3.5 days. Whilst this matches the national average, it again highlighted that the reason for the delay in discharge was the waiting period for endoscopy. We estimate that by reducing the stay in this group from 3.5 days to two days, we could save 21 bed days per year.

Two patients admitted to the HDU were inappropriate referrals, as both were at low risk and did not require any blood transfusion. Four high-risk patients requiring intensive monitoring were not admitted to the HDU. Although 'no bed in HDU' was the reason in one case, we felt that the lack of guidelines for the junior doctors for admission to the HDU was the main reason. Central venous pressure (CVP) was only monitored in one patient. This again is not ideal, as the majority of patients admitted to the HDU should warrant CVP monitoring. The surgical referral rate was also too low. There are reports to suggest that early operation in the elderly results in a better outcome, although this is not necessarily the case in the younger age group ${ }^{(5)}$. It is vital to have joint medical/surgical management in the high risk group.

\section{RECOMMENDATIONS}

In the short term we have formulated and implemented guidelines for the immediate management of upper gastrointestinal bleed. In the longer term, more resources would be required and more trained endoscopists would be necessary to facilitate endoscopy within twenty-four hours. This would enable the early discharge of inpatients or treatment as an outpatient ${ }^{(6)}$, especially in the low risk group, with resultant cost savings for the trust. A proforma has also been designed to facilitate a prospective audit to evaluate the impact of the implementation of the guidelines.

\section{REFERENCES}

1 Rockall TA, Logan RFA, Devlin HB, Northfield TC Incidence and mortality from acute upper gastrointestinal haemorrhage in the United Kingdom. $\mathrm{Br}$ Med J 1995;311:222-226

2 Lennard-Jones JE et al Guidelines for good practice in and audit of the management of upper gastrointestinal haemorrhage. Report of a joint working group of the British Society of Gastroenterology, the research unit of the Royal College of Physicians of London and the audit unit of the Royal College of Surgeons of England. J Roy Coll Phys London 1992;26(3):281-289

3 Rockall TA, Logan RFA, Devlin HB, Northfield TC Risk assessment following acute upper gastrointestinal haemorrhage. Gut 1996;38:316-321

4 Rockall TA, Logan RFA, Devlin HB, Northfield TC Selection of patients for early discharge or outpatient care after acute gastrointestinal haemorrhage. Lancet 1995;347:1138-1140

5 Morris DL, Hawker PC, Brearley S et al Optimal timing of operation for bleeding peptic ulcer: prospective randomized trial. Br Med J 1984;288:1277-1280

6 Longstreth GF, Feitelberg SP Outpatient care of selected patients with acute non-variceal upper gastrointestinal haemorrhage. Lancet 1995;345:108-111 